\title{
Three-Dimensional Automatic Generation Magnetic Equivalent Circuit Using Mesh-Based Formulation
}

\author{
Y. Benmessaoud ${ }^{1 *}$, F. Dubas ${ }^{1}$, R. Benlamine ${ }^{2}$, and M.Hilairet ${ }^{1}$ \\ ${ }^{1}$ FEMTO-ST Institute, Univ. Bourgogne Franche-Comté, CNRS, Département ENERGIE, Parc technologique, 2 avenue Jean Moulin, \\ F-90000 Belfort Cedex, France. \\ 2 VEDECOM Institute, Versailles, France. \\ Email: youcef.benmessaoud@femto-st.fr
}

\begin{abstract}
In this paper, a three-dimensional (3-D) generic magnetic equivalent circuit (MEC) using mesh-based formulation was developed for the electrical engineering applications. The particularity of this model consists in a discretization with hexahedral mesh elements, which can be chosen by the designer. For example, the 3-D generic MEC has been applied to a U-cored static electromagnetic device. In order to confirm the effectiveness of the proposed technique, the semianalytic results have been compared with those obtained using 3-D finite-element analysis (FEA). The computation time is divided by 3 with an error less than $1 \%$.
\end{abstract}

Index-terms-Automatic generation, discretization, magnetic equivalent circuit, mesh element, three-dimensional.

\section{CONTEXT AND OBJECTIVES OF THIS PAPER}

Over the years, many modeling techniques for the electromechanical systems were published in significant journals. These can be classified in various methods [1]: Lehmann's graphical, numerical (i.e., finite-element, finitedifference, boundary-element,...), equivalent circuit (i.e., electrical, thermal, magnetic,...), Schwarz-Christoffel mapping, Maxwell-Fourier (i.e., multi-layers models, eigenvalue model, subdomain technique, and hybrid models). In this paper, the scientific focus is dedicated to the electromagnetic modeling by $\mathrm{MEC}$, which is the analogy with electric equivalent circuit. It presents a strong advantage in simplifying the analysis of magnetic systems, by using Kirchhoff's current or voltage law, that can be translated by Gauss' and Ampere's laws in MEC.

The MEC approach was first introduced in 1940's by Roters [2], which has defined the basic principles and elements of MEC in electromagnetic devices. Laithwaite [3] (1967) and Carpenter [4] (1968) demonstrated that the technique may be extended to cover AC electromagnetic systems (e.g., the electrical machines) by including the duality between the electrical and magnetic equivalent circuit. Ostovic [5] (1988) incorporated the motion and saturation by using the concept of permeance function. Since many researchers have improved this method [6]-[10], viz., saturation effect, reluctance shape, magnets magnetization direction, MEC discretization,..., rotor moving, hybrid models, and automatic generation reluctance. This modeling technique presents a compromise between analytic and numeric methods concerning accuracy, computation time, and optimization process. MEC was improved using graphical method to generate automatic's reluctance mesh.

Many works have been done in the past. Frequently, MEC are based on the unidirectional (UD) blocks (e.g., in the stator/rotor yoke, teeth,...). These blocks can also be used in the air-gap by a permeance function, but it remains less accurate. Moreover, the choice of the torque calculation method is affected. As an example, the Maxwell's stress tensor can be applied only when the two component of the magnetic flux density can be calculated. Thus, the bidirectional (BD) or tridimensional (TD) blocks are necessary to calculate accurately the electrical machines performances (e.g., torque, magnetic forces, losses,...). Recently, many studies are focused on the losses and non-conventional electrical machines topologies such as the axial-flux machines, where the radial component can not be neglected comparing to tangential/axial components. Therefore, TD blocks are needed. A 3-D MEC is disfavored because it is time consuming. However, the evolution of programming software gives more interest to this type of modeling, e.g., many Matlab functions (Kronecker product, circshift, identity matrix,...) can help to simplify programming and make it more visible and comprehensible. Due to high number of contributions dealing with MEC, this paper will only summarize those that have focused on the 3-D MEC.

In [11]-[12], a 3-D model was developed to study a claw pole alternator by using UD permeance in the three directions. The same topology having an asymmetric structure along the rotor axis have been studied in [13]. This technique is also applied in [14] to study a double excitation synchronous machine, while a 3-D model was done basing on the direct and quadratic axes in [15]. A 3-D model for linear machine with surface-mounted magnets was developed by using hexahedral or fan-shaped elements, where the rotor motion was presented by 3-D function using the Fourier's series [16]-[17]. The same model is used in [18] to study the magnet arrangement. It has also been applied to calculate the thrust force in the linear induction motor by 3-D time-stepping MEC [19]. In [20], a 3-D MEC based on [16]-[17] was used for the accurate and efficient analysis of hybrid stepping motor by using trapezoidal elements, while [21] developed a 3-D model for the magnetic field analysis in Brushless DC motors by using distributive magnetic circuit parameters. A 3-D MEC is needed to study interbar currents and the resulting axial fluxes in healthy and faulty induction machines [22], also to study spherical machines by dihedral cone shape or to study losses [23]. A 3$\mathrm{D}$ MEC model can be combined with analytical model as in [24], where the air-gap is based on the formal resolution of Maxwell's equations while the stator is modeled by MEC. This makes it possible to take into account the saturation effect in the stator and decreasing the computation time due to the rotor motion. In [25], a 3-D MEC based optimum design of axialflux magnets machines has been presented. The aim is to find 


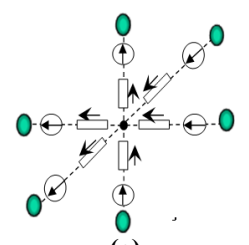

(a)

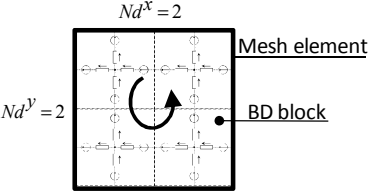

(d)

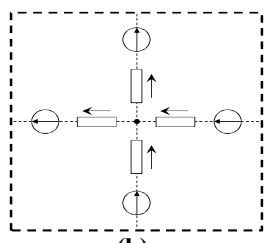

(b)

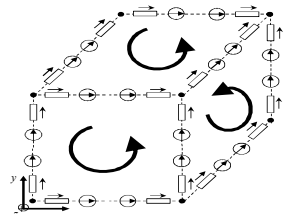

(c)

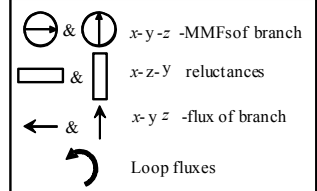

(e)

Fig. 1: Mesh: (a) TD block, (b) BD block, (c) Hexahedral, (d) Mesh element, and (e) legend.

an optimum torque density when keeping a motor volume at the desired value. In [26], the same authors extended his previous work by incorporating an axial segmentation, to make studies under different operating conditions. In order to calculate the iron losses in a three-phase laminated-core variable inductor machine, a coupled model between a 3-D MEC and eddy-current model circuit by using fan-shaped elements is realized [27]. A 3-D model can be obtained by extending a 2-D or quasi 3-D model [28]. In [29] discussed the 3 -D modeling approach by implementing the variable-sized reluctance network distribution. This modeling type is used for the force calculation based on the Maxwell's stress tensor [30] and was applied to study induction motor [31].

All these references suggested models more or less generic based on the nodal-mesh method. Although in [32], it is proved that the mesh-based approach is better than the nodal one (i.e., convergence and calculation time). Actually, there is no 3-D model based on the automatic generation reluctances by using mesh-based formulation to build the equation system to solve. Thus, in this paper, a 3-D automatic generation MEC will be presented. The particularity of this model consists in a discretization with hexahedral mesh elements [see Fig. 1(c)] using mesh-based formulation (i.e., Kirchhoff's voltage law) to resolve the equations system. In section II, the discretization and the automatic generation will be described. Then in section III, the 3-D generic MEC formulation is presented. In order to validate the developed model, a Ucored static electromagnetic device is studied in section IV and the results are compared to 3-D FEA [33]. It is worth to mention that this approach can cover even dynamic devices if the motion is incorporated, and could be easily extended to study linear machines. For the rotary machines, only the shape of the elements change, but the reasoning is still the same.

\section{DiscretiZATION AND AUTOMATIC GENERATION}

In what follow, it is defined a magnetic branch as magnetic reluctance in series with the magnetomotive force (MMF). The discretization is based on cutting plans in parallel to the three spaces planes of Cartesian system. In numerous publications, a 3-D mesh element was defined as an element constituting 6 magnetic branches connected by one node, which represent the unknowns scalar magnetic potential [see Fig. 1(a)]. In this work, the reluctance mesh element are obtained by connecting 16 BD blocks [see Fig. 1(b)] in the manner to build a volume mesh element like [see Fig. 1(c)]. In the same figure, it can be remarked that each volume element contain 24 magnetic reluctances and 6 loop fluxes.

The combination of different BD blocks of the three space planes lead also to TD blocks, one should note that the unknowns, are the loops fluxes. Furthermore, branch fluxes can be obtained by topological matrix. It is noted that the flux can flow only in one direction between two nodes.

\section{A. Concept of Mesh Element}

To make the model more flexible, each device might be discretized in a set of surface mesh element. Each mesh element is constituted at least by one BD block, and can be discretized into a high number of BD blocks, as shown in Fig. 1(d). The mesh element that belong to the YX plane discretized in two BD blocks in both $y$-and $x$-axis. One should note that the simulation time and the results precision rise with the increasing number of BD blocks.

A 3-D generic mesh reluctance box illustrated in Fig. 2(a) can be used to model any electromagnetic device. It can be decomposed in a set of vertical, horizontal and longitudinal arrows it is distinguished $\left\{n, n^{\prime}, n^{\prime \prime}\right\}$ numbers of element mesh in the $x$-, $y$ - and $z$-axis respectively. In Fig. $2, N d_{*}^{\text {\# }}$ represents the number of discretization in the $\mathbf{\square}$-axis, for the surface mesh element *. So, each 2-D surface mesh element can be identified by its triple $\left(N d_{i}^{x}, N d_{j}^{y}, N d_{k}^{z}\right)$, $\left(N d_{i}^{x}, N d_{k}^{z}, N d_{j}^{y}\right)$ and $\left(N d_{j}^{y}, N d_{k}^{z}, N d_{i}^{x}\right)$ which are parallel respectively to the $\mathrm{XY}, \mathrm{XZ}, \mathrm{YZ}$ planes. The third dimension means the slice number as it can be remarked in the Fig. 2(b), (c) and (d). Through the Figs. 2, it can be remarked that all mesh elements are independent. Two main advantages can be derived from this technique, the first one consists on easiness to affect materials for each mesh element, the second one consists on the local discretization. As an example, it can be affected a material with permeability $\mu_{311}^{x y}$ to the mesh element spotted by $\left(N d_{3}^{x}, N d_{1}^{y}, N d_{1}^{z}\right)$ that belongs to $\mathrm{XY}$ plane, illustrated in gray in Fig. 3. If precision is needed in the same mesh element, a number of BD blocks can be increased in all axes, here, it is chosen $\left(N d_{3}^{x}=3, N d_{1}^{y}=2, N d_{1}^{z}=1\right)$.

Namely 6 BD blocks, but the number of BD blocks can be grown more. This yields to model all regions of any electromagnetic device by taking into account the material nonlinearity, or for particular studies like influence of mechanical stress on the magnetic permeability, default materials, etc.

\section{B. Branch Numbering}

As it is explained before, the discretization is applied on the three axis of Cartesian system. Thus discretization are linked directly with the number of BD blocks constituting one mesh element, that is to say magnetic reluctances, loop fluxes, potential nodes numbers depend on the discretization. TABLE I resumes the number of magnetic reluctances and potential node in one line parallel to a given axis of one slice that belong to a given plane. The number of loop fluxes $N_{\psi}$ for the slices parallel to $\mathbf{\square}$ plane is given as follow

$$
N_{\psi}=\frac{1}{4} \times\left\{\begin{array}{l}
P \times M \times n \text { in the XY plane } \\
P \times N \times m \text { in the XZ plane } \\
M \times N \times p \text { in the XZ plane }
\end{array}\right.
$$

where $\{P, M, N, p, m, n\}$ are the numbers given in TABLE I.

For $\left[\Re_{x}\right]$ and $\left[\Re_{y}\right]$, the priority is given to $x$-axis from the left to the right of slice which is parallel to XY plane, then to $y$ axis direction from the top to the bottom of the slice, furthermore to $z$-axis direction. For the $\left[\mathfrak{R}_{z}\right]$, the priority is 


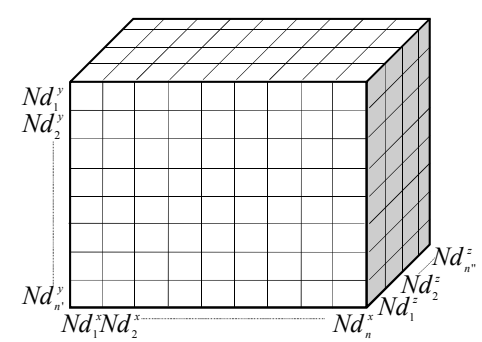

(a)

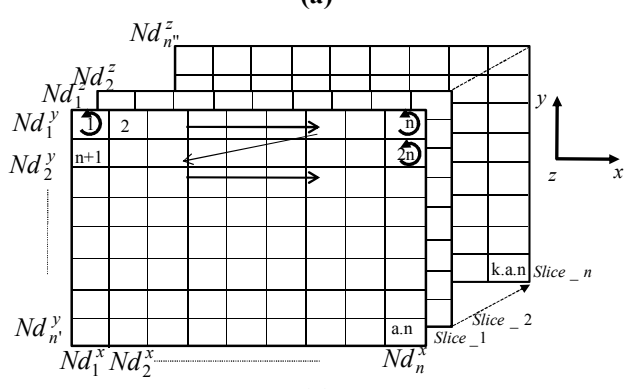

(b)

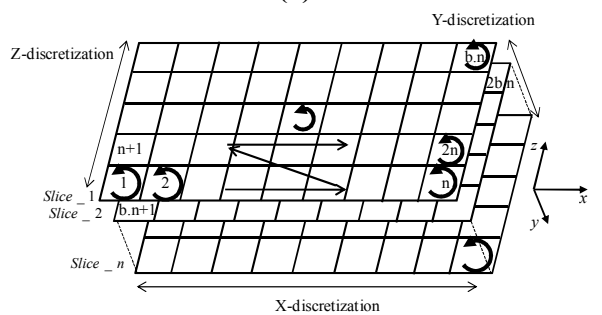

(c)

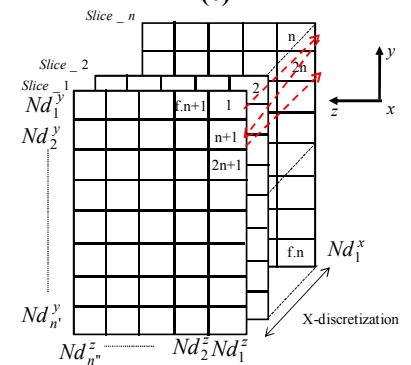

(d)

Fig. 2: (a) 3-D box, (b) XY plane, (c) XZ plane, (d) YZ plane.

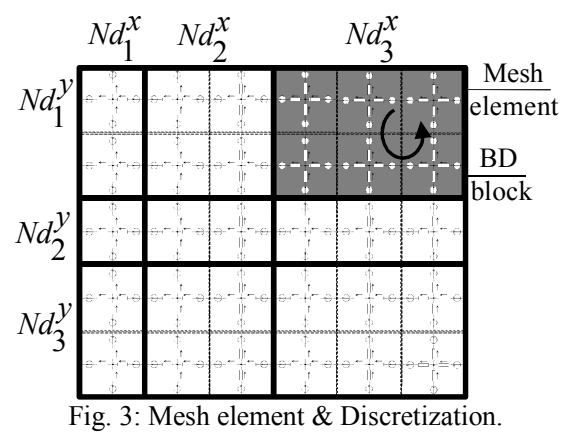

TABLE I

NuMBER OF RELUCTANCES AND NODES THROUGH EACH PLANE.

\begin{tabular}{|c|c|c|l|}
\hline Axis & $\begin{array}{l}\text { Branch number of } \\
\text { one line }\end{array}$ & $\begin{array}{l}\text { Potential node } \\
\text { number of on line } \\
\text { for each slice }\end{array}$ & $\begin{array}{l}\text { Total number } \\
\text { branch of all } \\
\text { slices }\end{array}$ \\
\hline $\boldsymbol{x}$ & $P=2 * \sum_{1}^{n} N d_{i}^{x}-2$ & $p=\sum_{1}^{n} N d_{i}^{x}$ & $P \times m \times n$ \\
\hline $\boldsymbol{y}$ & $M=2 * \sum_{1}^{n^{\prime}} N d_{i}^{y}-2$ & $m=\sum_{1}^{n^{\prime}} N d_{i}^{y}$ & $p \times M \times n$ \\
\hline $\boldsymbol{z}$ & $N=2 * \sum_{1}^{n^{\prime \prime}} N d_{i}^{z}-2$ & $n=\sum_{1}^{n^{\prime \prime}} N d_{i}^{z}$ & $p \times m \times N$ \\
\hline
\end{tabular}

given to $x$-axis from the left to the right of slice which is parallel to XZ plan, then to $z$-axis direction from the top to the bottom of the slice, furthermore to $y$-axis direction.

In Fig. 2, the loops are numerated from the left to the right then from the top to the bottom of slices. The priorities are given to the first dimension, which is $x$-axis direction in the three planes, and then the second dimension is given to the height, which means $y$-axis direction in the (XY - YZ) planes, and $z$-axis direction in the $\mathrm{XZ}$ plane. Finally, the slices are extruded in the third missing direction. One should note that all parallel slices that belong to a given plane have the same number of loops and branches.

\section{3-D GENERIC MEC FORMULATION}

Using the Maxwell's equations as well as the magnetic material equations, the 3-D generic MEC can be governed by:

$$
\begin{gathered}
{[F]-[\chi] \cdot[\Re] \cdot[\chi]^{T} \cdot[\psi]=0} \\
{[F]=[\chi] \cdot[\mathrm{MMF}]} \\
{[\phi]=[\chi]^{T} \cdot[\psi]}
\end{gathered}
$$

where $[\Re]$ is the diagonal matrix of magnetic reluctances in each axis, $[\psi]$ the loop fluxes vector in all planes, $[\phi]$ the branch fluxes vector in all axes, $[F]$ the loop MMFs of all planes, and $[\chi]$ the topological matrix in all planes.

\section{A. Magnetic Reluctance}

It is well known that the magnetic reluctance depend in the geometries of the flux tube and the physical parameters of materials under following formula:

$$
[\Re]=\frac{1}{\mu_{0}} \cdot \frac{[l]}{\left[\mu_{r}\right] \cdot[S]}
$$

where $\mu_{0}$ is the vacuum permeability; and $[l]$, [S], and $\left[\mu_{r}\right]$ are respectively the flux tube length, the flux tube section, and the relative magnetic permeability matrixes.

(2a) contain all branches reluctances and arranged as follow

$$
[\Re]=\left[\begin{array}{ccc}
{\left[\mathfrak{R}_{x}\right]} & 0 & 0 \\
0 & {\left[\mathfrak{R}_{y}\right]} & 0 \\
0 & 0 & {\left[\mathfrak{R}_{z}\right]}
\end{array}\right]
$$

The reluctance matrixes in the XY plane are defined by

$$
\left[\Re_{\mathbf{\Xi}}\right]=\left[\begin{array}{ccc}
{\left[\mathfrak{R}_{\mathbf{a}_{1}}^{x y}\right]} & 0 & 0 \\
0 & \ddots & 0 \\
0 & 0 & {\left[\mathfrak{R}_{\mathbf{\square}_{-}}^{x y}\right.}
\end{array}\right]
$$

where can be replaced by $x$ or $y$, and $\left[\mathfrak{R}_{\mathbf{C}_{k}}^{x y}\right]$ represents the reluctances matrix of $k^{\text {th }}$ slice in the $x$ - and $y$-axis to the XY plane:

$$
\begin{aligned}
{\left[\Re_{x_{-} k}^{x y}\right] } & =\left[\begin{array}{ccc}
\Re_{11} & \ldots & \Re_{1 P} \\
\vdots & \ddots & \vdots \\
\Re_{m 1} & \ldots & \Re_{m P}
\end{array}\right] \\
{\left[\Re_{y_{-} k}^{x y}\right] } & =\left[\begin{array}{ccc}
\Re_{11} & \ldots & \Re_{1 p} \\
\vdots & \ddots & \vdots \\
\mathfrak{R}_{M 1} & \ldots & \Re_{M p}
\end{array}\right]
\end{aligned}
$$


The reluctance matrixes in $\mathrm{XZ}$ plane are defined by

$$
\left[\Re_{z}\right]=\left[\begin{array}{ccc}
{\left[\Re_{Z_{-} 1}^{x Z}\right]} & 0 & 0 \\
0 & \ddots & 0 \\
0 & 0 & {\left[\mathfrak{R}_{z_{-} m}^{x Z}\right]}
\end{array}\right]
$$

where $\left[\mathfrak{R}_{z_{-} j}^{x z}\right]$ represents the reluctances matrix of $j^{\text {th }}$ slice in the $z$-axis to the $\mathrm{XZ}$ plane:

$$
\left[\Re_{Z_{-} j}^{x Z}\right]=\left[\begin{array}{ccc}
\mathfrak{R}_{11} & \ldots & \mathfrak{R}_{1 p} \\
\vdots & \ddots & \vdots \\
\mathfrak{R}_{N 1} & \ldots & \mathfrak{R}_{N p}
\end{array}\right]
$$

Then, the matrixes will be rearranged line by line and slice by slice in the manner to be diagonal.

\section{B. Geometries Parameters for Magnetic Reluctances}

The geometric parameters of each element mesh are given in TABLE I where $\left(L_{i}^{x}, L_{j}^{y}, L_{k}^{z}\right)$ and $\left(l_{i}{ }^{x}, l_{j}{ }^{y}, l_{k}{ }^{z}\right)$ are respectively the length of each reluctance branch and element mesh in different axis, as it can be seen in Fig. 4. The length and sections, consequently magnetic reluctances, are treated as function of $N d^{*}$ where ${ }^{*}$ can be replaced by $x, y$ or $z$ while can be replaced by $i, j$ or $k$.

\section{Relative Magnetic Permeability Matrix}

The relative magnetic permeability matrix has the same number of element as the length and section matrix are arranged in the same manner. It allows to affect the materials to each device part. One permeability matrix in each axis direction is distinguished, this make very easy to switch to another devices topologies, viz.,

$$
\left[\mu_{r}\right]=\left[\begin{array}{ccc}
{\left[\mu_{r x}^{x, y}\right]} & 0 & 0 \\
0 & {\left[\mu_{r y}^{x, y}\right]} & 0 \\
0 & 0 & {\left[\mu_{r z}^{x, z}\right]}
\end{array}\right]
$$

where $\left[\mu_{r *}^{\mathbf{*}}\right]$ represents the relative magnetic permeability matrix in the $*_{\text {-axis to }}$ the plane with $\left[\mu_{r x}^{x y}\right]$ of dimension $[m \times P \times n],\left[\mu_{r y}^{x y}\right]$ of dimension $[M \times p \times n]$ and $\left[\mu_{r z}^{x z}\right]$ of dimension $[N \times p \times m]$.

\section{MMF Sources}

The MMFs matrix are managed exactly like reluctances, the only difference it consist in matrix dimension in which MMFs present a vector equal to a total number of branches, viz.,

$$
[M M F]=\left[\begin{array}{l}
M M F_{x} \\
M M F_{y} \\
M M F_{z}
\end{array}\right]
$$

The distribution of MMF for one coil was chosen to be trapezoidal as illustrated in Fig. 6 . The two zones $\{2,4\}$ present the ampere turns $N_{t} \cdot i_{\max }$ in one coil (e.g., two slots in electrical machine) while the surrounded region by the coil is the magnetic circuit (e.g., the tooth in electrical machine).

All BD blocks in the $y$-axis have the same values of MMFs. The MMFs value differs between discretization in the $x$-axis depending on the MMF's slope.

\section{E. Topological Matrix}

The topological matrix is given by

$$
[\chi]=\left[\begin{array}{ccc}
{[\chi]_{x}^{x y}} & {[\chi]_{y}^{x y}} & 0 \\
{[\chi]_{x}^{x z}} & 0 & {[\chi]_{z}^{x z}} \\
0 & {[\chi]_{y}^{y z}} & {[\chi]_{z}^{y z}}
\end{array}\right]
$$

In $[10]$, the elements $[\chi]_{i j}$ of this matrix are equal to:

$$
[\chi]_{i j}=\left\{\begin{array}{c}
+1 \text { if branch } \mathrm{j} \in \psi_{i}^{+} \\
-1 \text { if branch } \mathrm{j} \in \psi_{i}^{-} \\
0 \text { if branch } \mathrm{j} \notin\left(\psi_{i}^{+} \cup \psi_{i}^{-}\right)
\end{array}\right.
$$

where $\psi_{i}^{+}-$Branch and loop fluxes have the same direction, and $\psi_{i}^{-}-$Branch and loop fluxes have opposite directions.

To understand more an example is given in Fig. 6, while the TABLE III gives in the general manner how the matrixes are written with

- $\otimes:$ Kronecker product;

- $[\mathrm{I}]^{*}$ : Identity matrix of $*$ dimension where $*$ can be replaced by $\{M / 2, P / 2, N / 2, m, n, P\}$;

- $\left[Y_{*}\right]^{\star}:$ Topological sub-matrix in the $*_{\text {-axis to the }}$ plane and of $\star$ dimension;

- $[\chi]_{\mathrm{s}^{*}}$ : Topological matrix for the first slice in the $*$-axis to the plane;

- $\left[\begin{array}{ll}1 & 1\end{array}\right]$ appears due to the two branches in series (e.g., $B x 1$ and $B \times 2$ in Fig. 6).

The general equation for the $\mathrm{YZ}$ plane is not given because it doesn't respect a Kronecker operator, one should respect the axes branch and flux loop numeration. The topological matrix can be obtained rezoning by slice or by stage [see Fig. 2(d)] and lead to use some commands like circle shift in Matlab software.

TABLE II

LENGTH AND SECTIONS OF RELUCTANCES WITH DiSCRETIZATION.

\begin{tabular}{|c|c|c|}
\hline Reluctances & Length & Section \\
\hline$x$-axis & $L_{i}^{x}=\frac{l_{i}{ }^{x}}{2 \cdot N d_{i}^{x}}$ & $S_{d i}^{x}=\frac{l_{k}{ }^{z}}{N d_{k}^{z}} \frac{l_{j}{ }^{y}}{N d_{j}^{y}}$ \\
\hline$y$-axis & $L_{j}^{y}=\frac{l_{j}^{y}}{2 \cdot N d_{j}^{y}}$ & $S_{d j}^{y}=\frac{l_{i}{ }^{x}}{N d_{i}^{x}} \frac{l_{k}{ }^{z}}{N d_{k}^{z}}$ \\
\hline$z$-axis & $L_{k}^{z}=\frac{l_{i}{ }^{z}}{2 \cdot N d_{k}^{z}}$ & $S_{d k}^{z}=\frac{l_{i}^{x}}{N d_{i}^{x}} \frac{l_{j}^{y}}{N d_{j}^{y}}$ \\
\hline
\end{tabular}

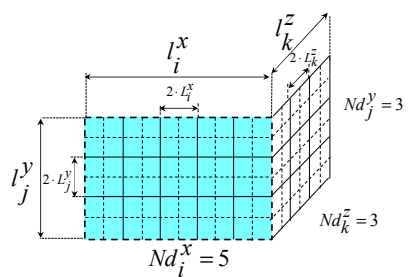

Fig. 4: Geometries parameters for magnetic reluctances.

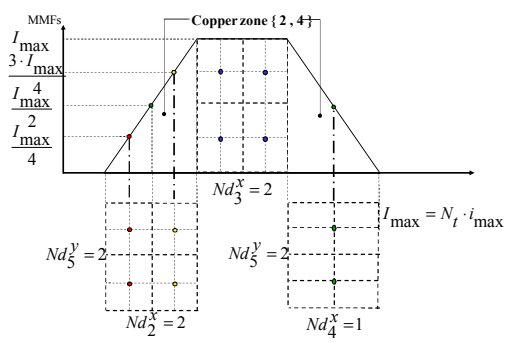

Fig. 5: MMF waveform for one coil. 


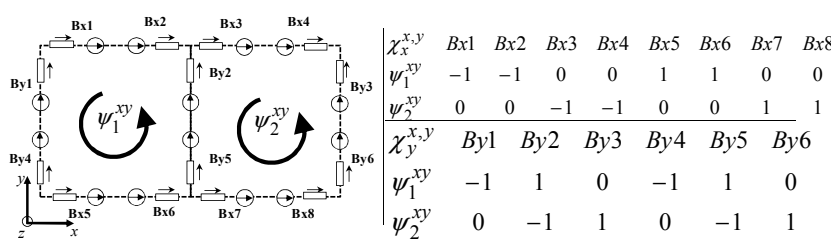

Fig. 6: Example about the topological matrix.

TABLE III

VARIOUS MATRIXES OF THE TOPOLOGICAL MATRIX.

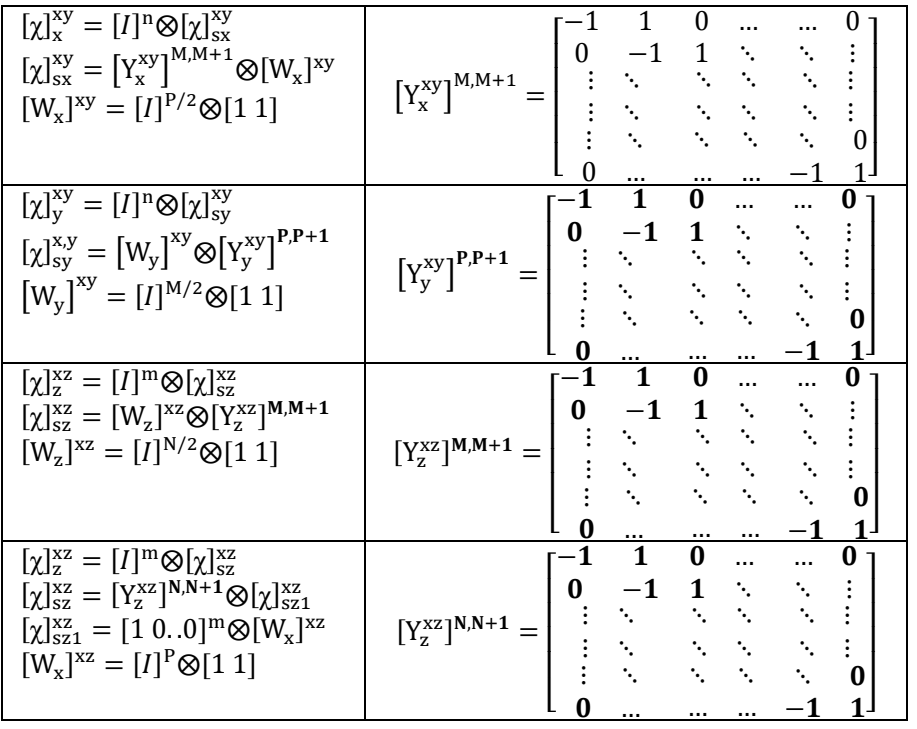

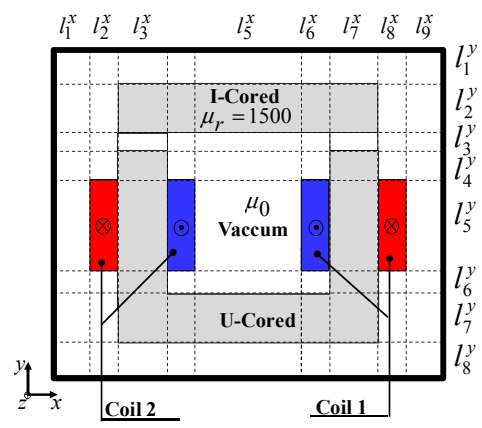

(a)

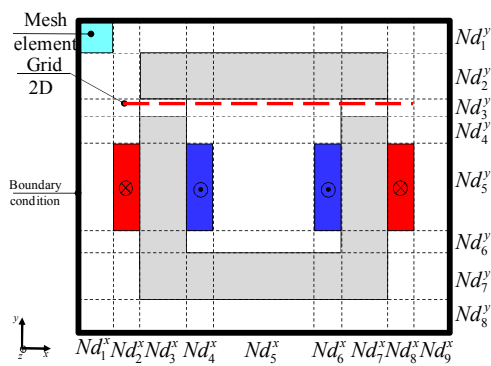

(b)

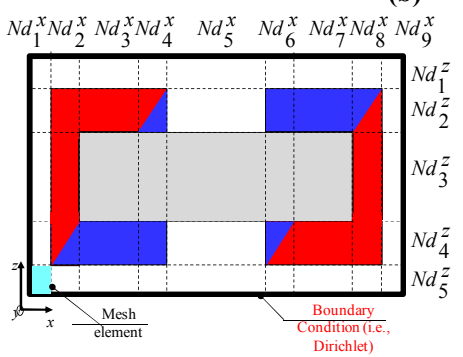

(c)

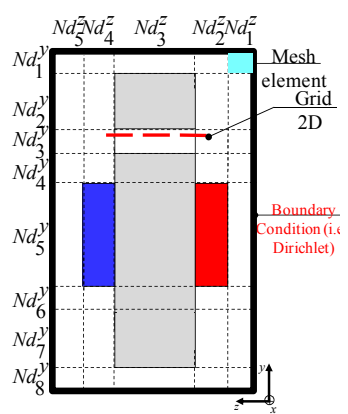

(d)

\section{ApPliCAtion to U-CORED Static Electromagnetic DEVICE}

\section{A. Description}

In this section, the performed model is applied to a U-cored static electromagnetic device with a mobile armature as shown in Fig. 7(a). Two coils supplied by opposite current with the same amplitude are located in both sides of the U-cored. The length of each element is also given in the same figure. Fig. 7(b), (c) and (d) give respectively the XY, XZ, and YZ plane view. We can see that the devices is discretized in 9 mesh elements in the $x$-axis, 8 mesh elements in the $y$-axis, and 5 mesh elements in the $z$-axis (see the TABLE IV). Numerical application is done using the data given on the TABLE V. By this discretization, it is obtained the numbers given in TABLE VI that lead to matrixes dimensions given in TABLE VII.

TABLE IV

MESH ELEMENT LENGTH AND DISCRETIZATION AXES.

\begin{tabular}{|c|c|}
\hline Axis & Length mesh element vector \\
\hline$x$ & $l^{x}=\left[\begin{array}{lll}l_{1}^{x} l_{2}^{x} l_{3}^{x} l_{4}^{x} l_{5}^{x} & l_{6}^{x} l_{7}^{x} & l_{8}^{x} l_{9}^{x}\end{array}\right]$ \\
\hline$y$ & 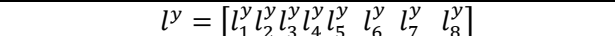 \\
\hline$z$ & $l^{z}=\left[\begin{array}{lllll}l_{1}^{z} & l_{2}^{z} & l_{3}^{z} & l_{4}^{z} & l_{5}^{z}\end{array}\right]$ \\
\hline Axis & Discretization vector \\
\hline$x$ & $N d^{x}=\left[N d_{1}^{x} N d_{2}^{x} N d_{3}^{x} N d_{4}^{x} N d_{5}^{x} N d_{6}^{x} N d_{7}^{x} N d_{8}^{x} N d_{9}^{x}\right.$ \\
\hline$y$ & $N d^{y}=\left[N d_{1}^{y} N d_{2}^{y} N d_{3}^{y} N d_{4}^{y} N d_{5}^{y} N d_{6}^{y} N d_{7}^{y} N d_{8}^{y}\right]$ \\
\hline$z$ & $N d^{z}=\left[N d_{1}^{z} N d_{2}^{z} N d_{3}^{z} N d_{4}^{z} N d_{5}^{z}\right]$ \\
\hline
\end{tabular}

TABLE V

NUMERICAL APPLICATION.

\begin{tabular}{|c|c|}
\hline Axis & Length mesh element vector \\
\hline$x$ & $\mathrm{l}^{\mathrm{x}}=\left[\begin{array}{lllllllll}1000 & 10 & 43 & 10 & 64 & 10 & 43 & 10 & 1000\end{array}\right.$ \\
\hline$y$ & $\mathrm{l}^{\mathrm{y}}=\left[\begin{array}{llllllll}1000 & 43 & 8 & 19 & 77 & 4 & 43 & 1000\end{array}\right]$ \\
\hline$z$ & 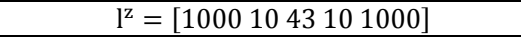 \\
\hline Axis & Discretization vector \\
\hline$x$ & $N d^{x}=\left[\begin{array}{lllllllll}1 & 1 & 11 & 1 & 10 & 1 & 11 & 1 & 1\end{array}\right]$ \\
\hline$y$ & $N d^{y}=\left[\begin{array}{llllllll}1 & 2 & 3 & 2 & 2 & 2 & 2 & 1\end{array}\right]$ \\
\hline$z$ & $N d^{z}=\left[\begin{array}{lllll}1 & 1 & 9 & 1 & 1\end{array}\right]$ \\
\hline
\end{tabular}

TABLE VI

NumBer of LoOP FluXes, BRANCH FluXes AND Potential NodE.

\begin{tabular}{|c|c|c|c|}
\hline Axis & $x$ & $y$ & $z$ \\
\hline $\begin{array}{c}\text { Branch number of one } \\
\text { line }\end{array}$ & $P=74$ & $M=28$ & $N=24$ \\
\hline $\begin{array}{c}\text { Potential node number } \\
\text { on line for each slice }\end{array}$ & $p=38$ & $m=15$ & $n=13$ \\
\hline $\begin{array}{c}\text { Branch number in all } \\
\text { slices }\end{array}$ & $\begin{array}{c}m \times P \times n \\
=14,430\end{array}$ & $\begin{array}{c}M \times p \times n \\
=13,832\end{array}$ & $\begin{array}{c}N \times p \times m \\
=13,680\end{array}$ \\
\hline $\boldsymbol{N}_{\psi}^{\boldsymbol{x y}}$ & 6,734 & 6,734 & 0 \\
\hline $\boldsymbol{N}_{\psi}^{x z}$ & 6,660 & 0 & 6,660 \\
\hline $\boldsymbol{N}_{\psi}^{y z}$ & 0 & 6,384 & 6,384 \\
\hline
\end{tabular}

TABLE VII

DIMENSIONS FOR VARIOUS MATRIXES OF 3-D GENERIC MEC

\begin{tabular}{|c|c|c|c|}
\hline Matrix & Dimension & Matrix & Dimension \\
\hline$\left[\Re_{x}\right],\left[\mu_{r x}^{x y}\right],\left[S_{x}\right],\left[l_{x}\right]$ & $74 \times 15 \times 13$ & {$\left[M M F_{x}\right]$} & $14,430 \times 1$ \\
\hline$\left[\Re_{y}\right],\left[\mu_{r y}^{x y}\right],\left[S_{y}\right],\left[l_{y}\right]$ & $28 \times 38 \times 13$ & {$\left[M M F_{y}\right]$} & $13,832 \times 1$ \\
\hline$\left[\Re_{z}\right],\left[\mu_{r z}^{x z}\right],\left[S_{z}\right],\left[l_{z}\right]$ & $24 \times 38 \times 15$ & {$\left[M M F_{z}\right]$} & $13,680 \times 1$ \\
\hline$[\Re]$ & $41,942 \times 41,942$ & {$[\psi]$} & $19,778 \times 1$ \\
\hline$[\chi]_{x}^{x y}$ & $6,734 \times 14,430$ & {$[\phi]$} & $41,942 \times 1$ \\
\hline$[\chi]_{y}^{x y}$ & $6,734 \times 13,832$ & & \\
\hline$[\chi]_{x}^{x z}$ & $6,660 \times 14,430$ & & \\
\hline$[x]_{z}^{x z}$ & $6,660 \times 13,680$ & & \\
\hline$[\chi]_{\mathrm{y}}^{\mathrm{yz}}$ & $6,384 \times 13,832$ & & \\
\hline$[\chi]_{z}^{\mathrm{yz}}$ & $6,384 \times 13,680$ & & \\
\hline
\end{tabular}

Fig. 7: U-cored static electromagnetic device in the various planes. 


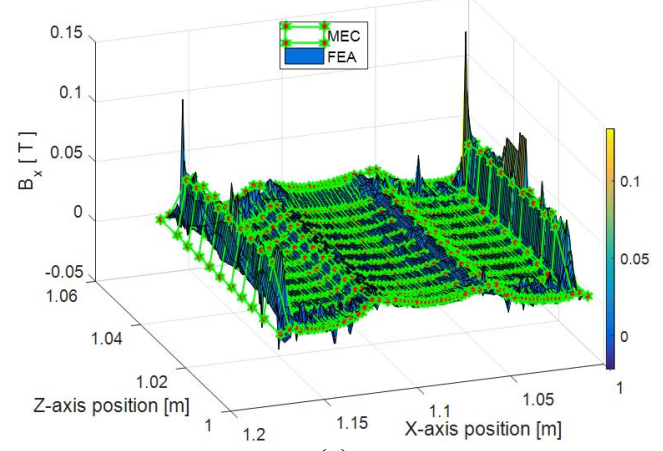

(a)

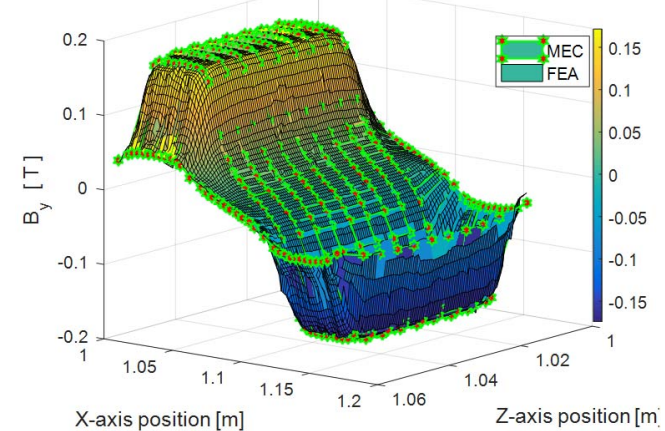

(b)

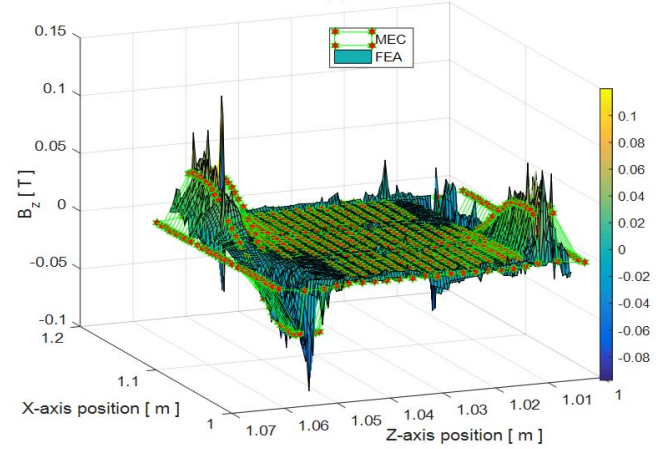

(c)

Fig. 8: Waveform of $\vec{B}$ in the 2-D grid of XZ plane with the 3-D generic MEC and 3-D FEA: (a) $x$-, (b) $y$ - and (c) $z$-components.

\section{B. Results Comparison with 3-D FEA}

The 3-D generic MEC was compared with 3-D FEA. The three components of $\vec{B}$ in the two-dimensional (2-D) grid [see Fig. 7(b) and (d)] of XZ plane are represented in Fig. 9. The comparison between the two methods is satisfied, the small difference is linked to the discretization of 3-D generic MEC. The computation time is divided by 3 with an error less than $1 \%$. It can be remarked through these figures that the leakage fluxes are taken into account, which are important in the exterior of the device than in the interior [see Fig. 9(a)].

\section{CONCLUSION}

In this paper, a 3-D generic MEC having an automatic mesh has been presented. The developed model is composed of hexahedral mesh elements obtained by superposing BD blocks in the three directions using the topological matrix. For clarity and more understanding, the various matrixes used in the 3-D generic MEC have been presented. The proposed approach allows to discretize the studied system according the three directions. The computation time depends on the number of mesh elements. However, it remains considerably lower than 3D FEA calculation time. In order to validate the model and verify its accuracy, a U-cored static electromagnetic device has been studied. The three components of the magnetic flux density according to the various planes are in good correlation with those obtained by 3 -D FEA. The computation time is divided by 3 with an error less than $1 \%$. The leakage fluxes can be calculated with high accuracy as well. It is worth to mention that the proposed approach can be applied to study dynamic electromagnetic devices, in particular electrical machines.

\section{ACKNOWLEDGEMENT}

This work was supported by RENAULT-SAS, Guyancourt France. This scientific study is related to the project "Conception optimale des chaines de Traction Electrique" (COCTEL) financed by the "Agence de l'Environnement et de la Maîtrise de l'Énergie” (ADEME).

\section{REFERENCES}

[1] F. Dubas, and K. Boughrara, "New scientific contribution on the 2-D subdomain technique in Cartesian coordinates: Taking into account of iron parts", Math. Comput. Appl., vol. 22, no. 1, p. 17, Feb. 2017.

[2] H.C. Roters, "Electromagnetic Devices", New York: Wiley \& Sons, 1941.

[3] E.R. Laithwaite, "Magnetic equivalent circuits for electrical machines", in Proc. IEE, vol. 114, no. 11, pp. 1805-1809, Nov. 1967.

[4] C.J. Carpenter, "Magnetic equivalent circuits," in Proc. IEE, vol. 115, no. 10, pp. 1503-1511, Oct. 1968.

[5] V. Ostovic, "A simplified approach to magnetic equivalent circuit modeling of induction machines", IEEE Trans. on Ind. Appl., vol. 24, no. 2, pp. 308-316, Mar./Apr. 1988.

[6] C.B. Rasmussen, and E. Ritchie, "A magnetic equivalent circuit approach for predicting pm motor performance", in Proc. IEEE IAS Annual Meeting, New Orleans, Louisiana, Oct. 05-06, 1997.

[7] F. Dubas, R. Benlamine, S-A. Randi, D. Lhotellier, and C. Espanet, "2-D or quasi 3-D nonlinear adaptative magnetic equivalent circuit, Part I: Generalized modeling with air-gap sliding-line technic", Applied Energy, under review.

[8] D.A. Philips, "Coupling finite elements and magnetic networks in magnetostatics", International Journal for Numerical Methods in Engineering, vol.35, no. 10, pp.1991-2002, Dec. 1992.

[9] M. Mirzayee, H. Mehrjerdi, and I. Tsurkerman, "Analysis of a high-speed solid rotor induction motor using coupled analytical method and reluctance networks", in Proc. ACES, Honolulu, Hawaii, Apr. 03-07, 2005.

[10] A. Delale, L. Albert, L. Gerbaud, and F. Wurtz, "Automatic generation of sizing models for the optimization of electromagnetic devices using reluctance networks", IEEE Trans. on Magn., vol. 40, no. 2, pp. 830-833, Mar. 2004.

[11] M. Hecquet, and P. Brochet, "Modeling of a claw-pole alternator using permeance network coupled with electric circuits", IEEE Trans. on Magn., vol. 31, no. 3, pp. 2131-2134, May 1995.

[12] M. Hecquet, and P. Brochet, "Validation of coupled electric permeance network model on a claw-pole alternator", in Proc. ICEM, Vigo, Spain, Sep. 10-12, 1996.

[13] S.H. Lee, S.O. Kwon, J.J. Lee, and J.P. Hong, "Characteristic analysis of claw-pole machine using improved equivalent magnetic circuit", IEEE Trans. on Magn., vol. 45, no. 10, pp. 4570-4573, Oct. 2009.

[14] K. Hoang, L. Vido, M. Gabsi, and F.Gillon "3D modeling of double excitation synchronous motor with reluctance network", in Proc. ICEM, Berlin, Germany, Sep.02-05, 2014.

[15] R-B. Mignot, C. Espanet, D. Chamagne, and T. Martin "Modeling of an axial flux PM motor using a 3D magnetic equivalent circuit" in Proc. VPPC, Coimbra, Portugal, Oct. 27$30,2014$. 
[16] J. Hur, S-B. Yoon, D-Y. Hwang, and D-S. Hyun, "Analysis of PMLSM using three dimensional equivalent magnetic circuit network method", IEEE Trans. on Magn., vol. 33, no. 5, pp. 41434145, Sept. 1997.

[17] J. Hur, S-B. Yoon, D-Y. Hwang, and D-S. Hyun, "Dynamic analysis of radial force density in brushless dc motor using 3-D equivalent magnetic circuit network method", IEEE Trans. on Magn., vol. 34, no. 5, pp. 3142-3145, Sep. 1998.

[18] I.S. Jung, J. Hur, and D.S. Hyun, "3-D analysis of permanent magnet linear synchronous motor with magnet arrangement using equivalent magnetic circuit network method", IEEE Trans. on Magn., vol. 35, no. 5, pp. 3736-3738, Sep. 1999.

[19] J. Hur, H.A. Toliyat, and J-P. Hong, "3-D time-stepping analysis of induction motor by new equivalent magnetic circuit network model”,IEEE Trans. on Magn., vol.37, no. 5, pp. 3225-3228, Sep. 2001.

[20] Y.H. Kim, C.S. Jin, S. Kim, Y.D. Chun, and J. Lee, “Analysis of hybrid stepping motor using 3D equivalent magnetic circuit network method based on trapezoidal element”, Journal of Applied Physics, vol. 91, no. 10, pp. 8311-8313, May 2002.

[21] Y.D. Chun, and,S. Wakao, "Magnetic force characteristics according to the variation of asymmetric overhang ratio in brushless direct current motor", Journal of applied physics, vol. 93, no. 10 , May 2003

[22] H. Meshgin-Kelk, J. Milimonfared, and H.A. Toliyat, "Interbar currents and axial fluxes in healthy and faulty induction motors", IEEE Trans. on Ind. Appl., vol. 40, no. 1, pp. 128-134, Jan./Feb. 2004.

[23] B. Li, G.D. Li, and H.F. Li, "Magnetic field analysis of 3-DOF permanent magnetic spherical motor using magnetic equivalent circuit method", IEEE Trans. on Magn., vol. 47, no. 8, pp. 2127 2133, Aug. 2011.

[24] M. Mirzayee, M. Mirsalim, H. Gholizad, and S.J. Arani, "Combined 3D numerical and analytical computation approach for analysis and design of high speed solid iron rotor induction machines", in Proc. CEM, Aachen, Germany, Apr. 04-06, 2006.

[25] Y. Kano, K. Tonogi, T. Kosaka, and N. Matsui, "Optimization of axial-flux PM machines for improved torque density by simple non-linear magnetic analysis", in Proc. IEMDC, Antalya, Turkey, May 03-05, 2007.

[26] Y. Kano, T. Kosaka, and N. Matsui, "A simple nonlinear magnetic analysis for axial-flux permanent-magnet machines", IEEE Trans. on Ind. Elec., vol. 57, no. 6, pp. 2124-2133, Jun. 2010.

[27] K. Nakamura, S. Hisada, K. Arimatsu, T. Ohinata, K. Sakamoto, and O. Ichinokura, "Iron loss calculation in a three-phase-laminated-core variable inductor based on reluctance network analysis", IEEE Trans. on Magn., vol. 45, no. 10, pp. 4781-4784, Oct. 2009.

[28] B. Nedjar, S. Hlioui, L. Vido, Y. Amara, and M. Gabsi, "Hybrid excitation synchronous machine modeling using magnetic equivalent circuits", in Proc. ICEMS, Beijing, Japan, Aug. 20-23, 2011.

[29] M. Amrhein, and P.T. Krein, "3-D magnetic equivalent circuit framework for modeling electromechanical devices", IEEE Trans. on Energy Conv., vol. 24, no. 2, pp. 397-405, Jun. 2009.

[30] M. Amrhein, and P.T. Krein, "Force calculation in 3-D magnetic equivalent circuit networks with a Maxwell stress tensor", IEEE Trans. on Energy Conv., vol. 24, no. 3, pp. 587593, Sep. 2009.

[31] M. Amrhein, and P.T. Krein, "Induction machine modeling approach based on 3-D magnetic equivalent circuit framework", IEEE on Energy Conv., vol. 25, no. 2, pp. 339347, Jun. 2010.

[32] H.W. Derbas, J.M. Williams, A.C. Koening, and S.D. Pekarek, "A comparison of nodal- and mesh-based magnetic equivalent circuit models", IEEE Trans. on Energy Conv., vol. 24, no. 2, pp. 388396, Jun. 2009.

[33] Flux2D/3D. General Operating Instructions; Version 10.2.1; Cedrat S.A. Electrical Engineering: Grenoble, France, 2008. 